\title{
Pelatihan TOEIC untuk siswi-siswi Tata Busana SMK Muhammadiyah Bangunjiwo, Kasihan, Bantul, Yogyakarta
}

\author{
Luluk Iswati \\ Prodi Manajemen, Fakultas Ekonomi dan Bisnis, Universitas Muhammadiyah Yogyakarta, \\ Yogyakarta, Indonesia \\ *Corresponding Author \\ J1. Brawijaya, Tamantirto, Kasihan, Bantul, Yogyakarta \\ E-mail: 1uluk007@gmail.com \\ Received: \\ 18 June 2019 \\ Revised: \\ 11 October 2019

\section{Accepted:} \\ 18 November 2019 \\ Published: \\ 30 November 2019
}

\begin{abstract}
Abstrak
Kegiatan Program Kemitraan Masyarakat (PKM) ini bertujuan untuk meningkatkan kompetensi Bahasa Inggris siswi-siswi Tata Busana SMK Muhammadiyah Bangunjiwo dengan memberikan pelatihan TOEIC (Test of English as an International Communication). TOEIC merupakan standar alat ukur kemampuan Bahasa Inggris siswa-siswi lulusan SMK yang telah diterapkan oleh pemerintah melalui Kemendikbud. Sebagai jurusan yang baru dibuka di tahun ajaran 2017/2018, Jurusan Tata Busana SMK Muhammadiyah Bangunjiwo belum pernah mengadakan pelatihan maupun tes TOEIC untuk meningkatkan serta mengukur kemampuan Bahasa Inggris para siswanya. Pelatihan ini dilaksanakan selama 17 pertemuan, dimana 2 pertemuan diantaranya digunakan untuk pre-dan post-test TOEIC bagi para peserta. Sebanyak 13 peserta tercatat sebagai peserta pelatihan ini. Pre-test dan posttest dilaksanakan untuk mengukur capaian skor peserta sebelum dan setelah pelatihan. Hasil menunjukkan bahwa dari 13 peserta pelatihan, 3 peserta tidak masuk selama pelatihan dan tidak mengikuti pre dan post-test (tidak aktif), 4 peserta hanya mengikuti post-test, 3 peserta mengalami kenaikan skor, 2 peserta mengalami penurunan skor, dan 1 peserta skornya tetap. Secara keseluruhan dapat disimpulkan bahwa meskipun hasilnya tidak signifikan, ada sikap dan hal positif yang ditunjukkan para peserta. Indikatornya adalah jumlah peserta post-test yang meningkat (10 orang) dibandingkan pada saat pre-test (6 orang) sehingga dapat dikatakan bahwa motivasi peserta naik, dan jumlah peserta yang mengalami kenaikan skor (3 orang) lebih banyak daripada peserta yang mengalami penurunan skor (2 orang), sehingga bisa dikatakan bahwa pelatihan ini cukup efektif untuk menaikkan kompetensi Bahasa Inggris para peserta.
\end{abstract}

Kata kunci: TOEIC; kompetensi Bahasa Inggris; SMK

\section{Abstract}

This Community Partnership Service activity aimed to improve the competence of English students at SMK (Vocational High School) Muhammadiyah Bangunjiwo by conducting TOEIC (Test of English and International Communication) training. TOEIC is a standard of English language proficiency 


\begin{abstract}
measurement for SMK graduates who have been set by the government through the Ministry of Education and Culture. As a new department opened in the 2017/2018 school year, the Department of Clothing of SMK Muhammadiyah Bangunjiwo has never held a TOEIC training nor TOEIC test to improve and measure the English language skills of its students. In this program, the training was held for 17 meetings, of which 2 meetings were used for the TOEIC pre-and post-test for the participants. A total of 13 participants were listed as participants in this training. Pre-test and post-test were carried out to measure participants' scores before and after training. The results showed that out of 13 training participants, 3 participants did not participate in the training nor did they participate in the pre and post-test (inactive), 4 participants only followed the post-test, 3 participants got an increased score, 2 participants got a decreased score, and 1 participant got a constant score. Overall, it can be concluded that even though the results are not significant, there are positive attitudes and things shown by the participants. The indicator is the increasing number of post-test participants (10 people) compared to the pre-test (6 people) so that it can be said that the participants' motivation rises, and the number of participants who got an increased score $(3$ people $)$ is more than the participants who got a decreased score (2 people,) so that it can be said that this training is quite effective in increasing the English competence of the participants.
\end{abstract}

Keywords: TOEIC; English competence; vocational school

\title{
PENDAHULUAN
}

Di era global ini, tidak dapat dipungkiri bahwa peran Bahasa Inggris sebagai bahasa internasional sangat penting. Era globalisasi telah menuntut adanya sumber daya manusia yang handal, yang salah satunya ditengarai dengan kemampuan berkomunikasi menggunakan bahasa internasional, yaitu bahasa Inggris (Handayani, 2016). Berbagai aspek kehidupan sudah menuntut adanya kemampuan berbahasa Inggris, salah satunya adalah di bidang pendidikan dan di dunia kerja. Sekolah vokasi atau Sekolah Menengah Kejuruan adalah pendidikan tingkat menengah yang dirancang untuk menyiapkan lulusannya sebelum memasuki dunia kerja. Oleh karena itu, sekolah ini membekali anak didik dengan keterampilan maupun kompetensi praktis yang nantinya relevan serta bermanfaat untuk digunakan pada saat mereka memasuki dunia kerja sesuai dengan jurusannya masing-masing. Salah satu kompetensi yang harus dimiliki oleh anak didik Sekolah Menengah Kejuruan adalah kompetensi bahasa Inggris. Ini sesuai dengan Instruksi Presiden No. 9 Tahun 2016 yang menyatakan bahwa lulusan SMK harus memiliki daya saing tinggi yang salah satu indikatornya adalah dimilikinya kemampuan bahasa Inggris yang memadahi. Fakta yang ditemukan di lapangan menuntut adanya kemampuan bahasa Inggris para tamatan sekolah kejuruan untuk bisa memperoleh pekerjaan (Yuliana, 2016). Sedangkan bahasa Inggris mempunyai peran bagi lulusan sekolah vokasi yaitu "menghasilkan lulusan yang berwawasan global, mampu bersaing, dan memiliki kemampuan bahasa Inggris yang baik" (Fauzia, 2013). Para lulusan sekolah kejuruan harus siap untuk menghadapi permintaan pasar internasional dan juga mampu bersaing di era global (Kaimuddin, 2009). Sementara itu, pendidikan vokasi harus memegang peranan penting dalam menyiapkan tenaga kerja yang terampil.Salah satu keterampilan yang harus dimiliki oleh tiap lulusan sekolah vokasi adalah keterampilan dalam menggunakan bahasa Inggris (Umar, 2017). Kementrian Pendidikan dan Kebudayaan (Kemendikbud) menetapkan bahwa lulusan SMK harus memiliki kemampuan berbahasa Inggris pada level intermediate atau setara dengan skor TOEIC 405. Skor ini akan 
sulit dicapai apabila siswa tidak mendapatkan kesempatan yang cukup untuk menggunakan bahasa Inggris secara aktif maupun pasif, apalagi belum pernah mengikuti pelatihan TOEIC.

Untuk mempersiapkan lulusan SMK yang siap berkompetisi dengan memiliki kemampuan bahasa Inggris yang cukup, maka perlu diadakan program pembelajaran yang mengarah kepada peningkatan kompetensi Bahasa Inggris siswa-siswa SMK yang sesuai dengan kebutuhan mereka, yaitu yang erat kaitannya dengan dunia kerja. Untuk itu, program yang tepat untuk diberikan kepada siswa-siswa SMK yaitu pelatihan TOEIC (Test of English for International Communication). Salah satu hal utama yang membedakan TOEIC dengan tes kompetensi lainnya seperti IELTS dan TOEFL adalah konten TOEIC yang fokus pada bidang bisnis dengan menggunakan materi bahasa Inggris yang biasa dipakai dalam bidang tersebut (Umar, 2017). Oleh karena itu, peningkatan kemampuan Bahasa Inggris siswa-siswa sekolah kejuruan akan lebih tepat apabila menggunakan materi-materi yang bersumber pada TOEIC, karena selain akan bermanfaat langsung nantinya pada saat mereka memasuki dunia kerja, TOEIC juga merupakan standar ukur kemampuan Bahasa Inggris mereka sesuai yang sudah ditetapkan oleh pemerintah.

SMK Muhammadiyah Bangunjiwo membuka dua jurusan kompetensi keahlian, yaitu Jurusan Teknik dan Bisnis Sepeda Motor, dan Jurusan Tata Busana. Jurusan Tata Busana SMK Muhammadiyah Bangunjiwo merupakan jurusan yang baru dibuka pada tahun ajaran 2017/2018. Menurut Kepala Sekolah, sebagai angkatan pertama, jurusan ini baru memiliki siswi sebanyak 13 anak. Sebagai jurusan baru, belum ada kegiatan peningkatan kemampuan Bahasa Inggris siswa yang diselenggarakan melalui pelatihan TOEIC. Secara umum, kemampuan Bahasa Inggris siswa Tata Busana juga masih perlu ditingkatkan, sehingga setelah lulus nanti para lulusan menjadi lebih siap dan percaya diri dalam bersaing baik di dunia kerja maupun di jenjang pendidikan selanjutnya.

\section{METODE}

Guna mengatasi permasalahan seperti dikemukakan di atas, maka pengabdian kepada masyarakat skema Program Kemitraan Masyarakat ini difokuskan pada peningkatan kemampuan bahasa Inggris siswi-siswi Tata Busana SMK Muhammmadiyah Bangunjiwo Kasihan, Bantul, Yogyakarta melalui pelatihan TOEIC, memberikan pengetahuan tentang strategi serta kiat-kiat agar sukses dalam tes TOEIC, meningkatkan kemampuan berkomunikasi dalam bahasa Inggris yang berhubungan dengan dunia kerja, serta memberikan motivasi kepada para siswi dalam belajar bahasa Inggris agar menjadi lebih percaya diri dalam menggunakan bahasa Inggris maupun dalam mengerjakan soal-soal TOEIC.

Sedangkan untuk capaiannya adalah tersedianya modul pembelajaran TOEIC dan modul-modul pendukung peningkatan kemampuan bahasa Inggris yang bisa diakses siswi-siswi SMK Muhammadiyah Bangunjiwo dan dikelola pemakaiannya oleh pihak sekolah, serta meningkatnya skor TOEIC siswi-siswi Tata Busana SMK Muhammadiyah Bangunjiwo, Kasihan, Bantul, Yogayakarta (minimal 400) yang ditunjukkan dengan sertifikat TOEIC-Like test yang dikeluarkan oleh Language Training Centre (LTC) UMY.

Untuk menjalankan program pelatihan TOEIC bagi siswi-siswi Tata Busana SMK Muhammadiyah Bangunjiwo, Kasihan, Bantul, Yogyakarta perlu dirancang tahapan-tahapan yang sistematis agar pelatihan berjalan efektif dan sesuai planning. Berdasarkan teori Werther dan Davis langkah-langkah yang direkomendasikan dalam melaksanakan suatu program pelatihan adalah sebagai berikut (Ismailia, Budi, \& Zuhro, 2017):

1. Mengidentifikasi kebutuhan (need analysis). Dalam tahap ini, pelaksana kegiatan pengabdian melakukan survei ke lokasi mitra untuk mengidentifikasi kebutuhan-kebutuhan yang diperlukan berkaitan dengan penyelenggaraan pelatihan, sehingga nantinya dapat diberikan treatment yang sesuai. Secara konkret, yang akan dilakukan pada tahap ini adalah mengidentifikasi kebutuhan-kebutuhan dalam pelatihan TOEIC seperti ada tidaknya modul 
pelatihan, materi audio pelatihan, dan peralatan audio (speaker active). Sedangkan yang tidak kalah penting adalah memberikan pre-test kepada para siswi untuk menjajagi kemampuan bahasa Inggris mereka melalui TOEIC-Like test yang diadakan oleh lembaga bahasa yang kredibel (LTC UMY).

2. Menentukan sasaran-sasaran pelatihan (training program). Sasaran pelatihan ditentukan setelah kebutuhan-kebutuhan diidentifikasi. Menentukan sasaran program berarti merumuskan kondisi atau perilaku seperti apa yang ingin dicapai dan bisa terukur. Dalam konteks pengabdian ini, sasaran pelatihan yaitu meningkatnya kemampuan berbahasa Inggris siswi-siswi Tata Busana SMK Muhammadiyah Bangunjiwo, Kasihan, Bantul, Yogyakarta yang diukur dengan TOEIC-Like test dengan target skor minimal 400.

3. Membuat isi program (content of program). Isi program dibuat berdasarkan analisa kebutuhan dan sasaran pelatihan. Program yang disusun harus sesuai dengan apa yang dibutuhkan mitra dan mendapat persetujuan mitra. Dalam program pelatihan TOEIC ini, program yang akan diberikan adalah skill-skill yang dipelajari dalam TOEIC terutama reading dan listening. Skill-skill tersebut diberikan melalui pelatihan soal yang dituangkan dalam modul.

4. Mendesain prinsip-prinsip belajar (learning principles). Prinsip-prinsip belajar perlu ditentukan agar pembelajaran bisa berjalan efektif. Dalam program ini, pendekatan yang dipakai adalah student-centred learning, sehingga siswa akan lebih banyak terlibat secara aktif selama proses pelatihan. Selain itu, pelatihan TOEIC ini akan menggunakan teknik pengajaran yang bervariasi, yang sesuai dengan pendekatan student-centred learning. Teknik-teknik pembelajaran seperti group work dan pair work akan banyak diterapkan.

5. Melaksanakan kegiatan pelatihan. Setelah semua langkah di atas dilakukan, pelatihan dilaksanakan dengan berdasarkan sasaran-sasaran pelatihan yang telah ditentukan. Pada pelaksanaannya, pelatihan diselenggarakan sebanyak 17 sesi, 2 sesi diantaranya digunakan untuk pre-test dan post-test. Pelatihan diselenggarakan 2 kali seminggu dimulai bulan Januari 2019 dan berakhir bulan Mei 2019. Setelah pelatihan selesai, para peserta diberikan post-test TOEICL-like yang diselenggarakan oleh LTC UMY untuk mengukur kemampuan mereka setelah mereka diberikan pelatihan TOEIC.

\section{HASIL DAN PEMBAHASAN}

Pelatihan TOEIC ini diawali dengan memberikan pre-test TOEIC kepada para peserta dengan tujuan untuk mengetahui kemampuan awal mereka sebelum diberikan pelatihan. Untuk menjamin validitas dan reliabilitas hasil tes, maka tes dilaksanakan di lembaga bahasa yang kredibel, yang biasa melayani tes kompetensi bahasa Inggris untuk internal dan umum, serta mengeluarkan sertifikat TOEIC-like, yaitu Language Training Centre (LTC) UMY. Sebanyak 13 siswa yang terdaftar di kelas X Jurusan Tata Busana SMK Muhammadiyah Bangunjiwo didaftarkan untuk mengikuti tes. Hasil pre-test TOEIC ditunjukkan pada tabel 1 di bawah ini:

Tabel 1. Hasil pre-test TOEIC

\begin{tabular}{ccc}
\hline NO & Nama & Skor pre-test \\
\hline 1 & Adiannisa Quirella & Tidak hadir/tidak aktif \\
2 & Amanda Wulansari & 170 \\
3 & Anisa Liam Sari & Tidak hadir \\
4 & Febriani & 260 \\
5 & Fitri Nur Cahyani & Tidak hadir \\
6 & Nadia Bela W & Tidak hadir/tidak aktif \\
7 & Nadya Puspitasari & Tidak hadir \\
8 & Nurul Atika O & 280
\end{tabular}




\begin{tabular}{ccc}
9 & Rissa Nuraeni & 190 \\
10 & Sri Rahayu & 145 \\
11 & Tarysa Bella & Tidak hadir/tidak aktif \\
12 & Valen Flary E & Tidak hadir \\
13 & Winda Eka D & 265 \\
\hline
\end{tabular}

Tabel 1 di atas menunjukkan bahwa tingkat partisipasi para siswa dalam mengikuti pretest TOEIC bisa dikatakan rendah karena dari 13 siswa yang terdaftar di kelas X Jurusan Tata Busana, hanya 6 siswa yang datang mengikuti pre-test. Sebanyak 7 siswa tidak datang, 3 diantaranya dinyatakan sudah tidak aktif mengikuti kegiatan belajar mengajar di sekolah (jarang sekali masuk). Kurangnya motivasi dari para siswa untuk mengikuti tes dan kurangnya pengetahuan mereka tentang TOEIC serta manfaat apa yang mereka dapatkan pada saat mengikuti tes ditengarai sebagai penyebab utama rendahnya partisipasi peserta untuk mengikuti pre-test TOEIC. Setelah pre-test, semua peserta mendapatkan sertifikat TOEIC-like test yang dikeluarkan oleh LTC UMY.

Setelah pre-test, pelatihan diadakan dengan fokus pada peningkatan kemampuan siswa dalam menguasai kompetensi dalam TOEIC, meskipun dari pihak sekolah juga menghendaki agar Kompetensi Dasar untuk siswa kelas X SMK juga diajarkan. Dengan kata lain, pada praktiknya program pelatihan TOEIC ini juga diintegrasikan dengan materi pembelajaran yang mengarah pada pencapaian Kompetensi Dasar (KD) yang sudah ditetapkan dalam kurikulum SMK. Hal ini disebabkan oleh padatnya jadwal di sekolah sehingga sulit untuk menjadwalkan pelatihan ini di luar jadwal jam belajar. Pelatihan ini difokuskan untuk mengasah kemampuan peserta dalam membaca (reading) dan mendengarkan (listening). Untuk keterampilan membaca, para peserta mendapatkan materi dan latihan berupa teks fungsional pendek (short functional texts) yang berhubungan langsung dengan dunia kerja di antaranya catatan pengingatan (memo), jadwal (schedule), laporan (report), pengumuman (announcement), tanda-tanda (signs), petunjuk (directions),dan sebagainya. Sedangkan untuk materi mendengarkan, para peserta berlatih mendengarkan percakapan pendek antara 2 orang dalam konteks dunia kerja. Materi pelatihan TOEIC yang mencakup dua keterampilan (membaca dan mendengarkan), diambil dari modul pembelajaran TOEIC yang beredar di pasaran. Hal ini sejalan dengan Umar (2017), yang sebelumnya pernah melakukan penelitian yang bertujuan untuk meningkatkan keterampilan mendengarkan para siswa sekolah vokasi dengan menggunakan buku Barron's TOIEC Preparation Course. Kegiatan pelatihan TOEIC ditunjukkan dalam Gambar 1 berikut ini:

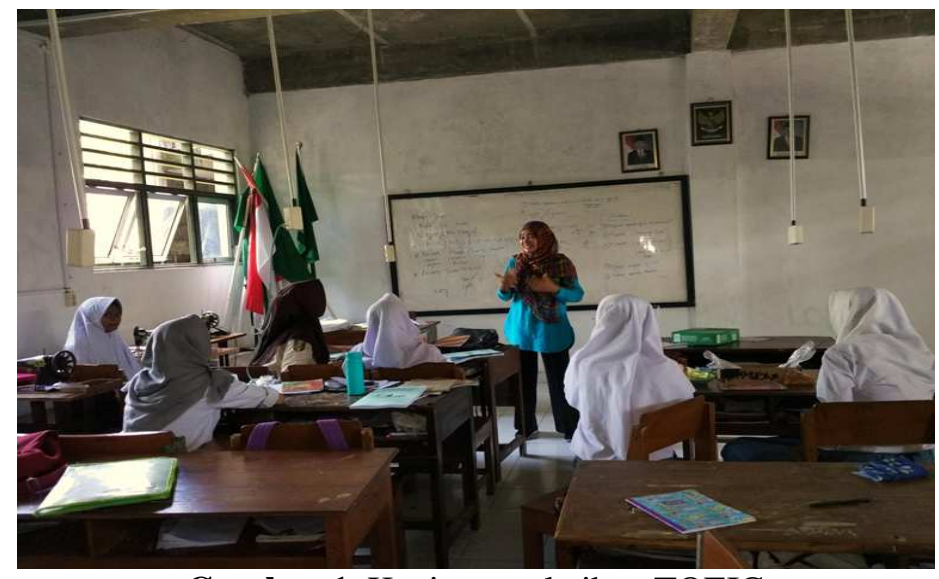

Gambar 1. Kegiatan pelatihan TOEIC 
Meskipun bahan utama pelatihan diambilkan dari buku pelatihan TOEIC, materi pelatihan tidak hanya berisi materi penguatan skill untuk TOEIC, tetapi juga berisi materi-materi yang sudah dirumuskan dalam Kompetensi Dasar Bahasa Inggris untuk SMK Kelas X. Ini diharapkan agar pelatihan yang berjalan cukup lama ini tidak hanya meningkatkan kemampuan Bahasa Inggris peserta yang diukur melalui TOEIC, tetapi juga mengakomodir tersampaikannya materi-materi yang tertuang dalam kurikulum, sehingga para siswa juga siap saat nanti menghadapi ujian sekolah. Selain itu, karena bersamaan dengan jadwal ujian teori dan praktek sekolah, serta kegiatan-kegiatan lainnya di sekolah, mengharuskan kegiatan pelatihan dijadwal ulang. Oleh karena itu, pada prakteknya kegiatan Pengabdian Kemitraan Masyarakat ini selesai dalam durasi waktu yang lebih lama, yaitu selama kurang lebih 5 bulan (Januari-Mei 2019). Untuk lebih lengkapnya, jadwal serta materi ajar selama pelatihan TOEIC tertuang dalam tabel 2 berikut:

Tabel 2. Jadwal dan materi pelatihan

\begin{tabular}{cll}
\hline Sesi & Hari,Tanggal & Materi \\
\hline 1 & Jumat, 18/1/2019 & Pre-test TOEIC \\
2 & Rabu, 30/1/2019 & Short functional texts: memo, schedule, menus \\
3 & Jumat, 1/2/2019 & Short functional texts: memo, schedule, menus \\
4 & Rabu, 6/2/2019 & Listening practice 1 \\
5 & Jumat, 9/2/2019 & Making memos, signs \\
6 & Rabu, 13/2/2019 & Comparison with one syllable \\
7 & Jumat, 15/2/2019 & Listening practice $2:$ Wh- questions \\
8 & Jumat, 22/2/2019 & Transactional texts \\
9 & Rabu, 27/2/2019 & Positive degree of comparison \\
10 & Jumat, 29/2/2019 & Asking for \& giving directions \\
11 & Jumat, 29/3/2019 & Conjunctions - prepositions \\
12 & Jumat, 5/4/2019 & Listening practice $3:$ photographs \\
13 & Rabu, 10/4/2019 & Comparative: text dialogs \\
14 & Jumat, 12/4/2019 & Reading practice: vocab enrichment \\
15 & Rabu, 24/4/2019 & Direction: practice giving direction \\
16 & Jumat, 26/4/2019 & Vocab enrichment \& reading comprehension \\
17 & Jumat, 3/5/2019 & Post-test TOEIC \\
\hline
\end{tabular}

Dalam kegiatan pelatihan TOEIC, pengajar tidak hanya menjelaskan materi maupun teori, tetapi juga memberi kesempatan kepada para siswa untuk mengerjakan latihan soal dan berinteraksi langsung baik dengan sesama siswa maupun dengan pengajar. Dengan kata lain, kegiatan belajar mengajar ini menggunakan pendekatan student-centred learning, dimana kegiatan belajar mengajar lebih banyak berpusat pada siswa. Student-centred learning merupakan konsep modern dalam teori pembelajaran yang berbeda dengan konsep tradisional yang dikenal dengan teacher-centred learning. Dalam teacher-centred learning, pengajar mendominasi kegiatan belajar mengajar dengan cara memberikan ceramah dalam durasi yang panjang, sehingga kesempatan siswa untuk melakukan praktek kegiatan lebih sedikit. Sebaliknya, dalam student-centred learning, para siswa bertanggung jawab sendiri dalam proses belajar yang mereka tempuh, sehingga mereka memiliki otonomi atau kemandirian dalam belajar (Jones, 2007). Kegiatan pembelajaran dengan pendektan student-centred learning lebih difokuskan pada pengasahan keterampilan dan kegiatan praktek para siswa, sehingga mereka bisa memecahkan masalah secara mandiri, tanpa banyak campur tangan pengajar (Young \& Paterson, 2007).

Selain memperhatikan pendekatan pembelajaran, teknik pembelajaran dalam pelatihan TOEIC ini juga perlu diperhatikan, agar bisa mencapai hasil yang maksimal. Dengan berbasis pada pendekatan student-centred learning, maka teknik pembelajaran banyak memberikan kesempatan 


\section{Indonesian Journal of Community Services}

Volume 1, No. 2, November 2019

http://jurnal.unissula.ac.id/index.php/ijocs

DOI: http://dx.doi.org/10.30659/ijocs.1.2.134-143

kepada para siswa untuk lebih aktif dalam kegiatan belajar. Teknik pengerjaan latihan soal juga divariasi, bisa secara individu, berpasangan (pair work), maupun berkelompok (group work). Hal ini bertujuan untuk memberikan variasi kegiatan agar siswa tidak cepat merasa bosan. Salah satu keuntungan group work adalah para siswa bisa saling berinteraksi dan bersosialisasi pada saat mereka belajar, dan mempunyai lebih banyak kesempatan untuk mengeskpresikan ide-ide mereka (Raja \& Ahmad Saeed, 2012). Oleh karena itu, dalam pelatihan TOEIC ini para peserta juga banyak melakukan aktivitas melalui group work, terutama apabila aktivitas tersebut berupa latihan penyelesaian soal-soal dengan tingkat kesulitan atau kerumitan yang cukup menantang.

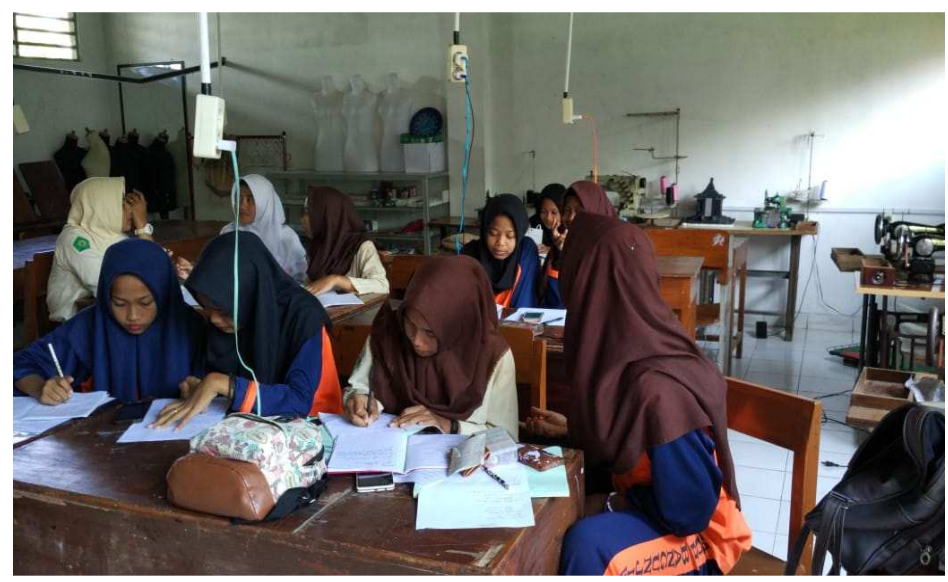

Gambar 2. Group work, salah satu bentuk kegiatan student-centred learning

Teknik pembelajaran lainnya yang juga tetap berpedoman pada student-centred learning yaitu pair work. Secara berpasangan, para siswa mengerjakan latihan dan memecahkan permasalahan yang diberikan, serta saling bertukar ide. Dengan memberikan latihan kosakata, para peserta akan menemui lebih sedikit kesulitan pada saat membaca, baik untuk memahami isi bacaan maupun untuk menjawab soal bacaan. Dalam gambar 3 di bawah ini, para peserta diberikan latihan untuk pengayaan kosakata mereka, yang nanti akan menunjang kemampuan membaca mereka.

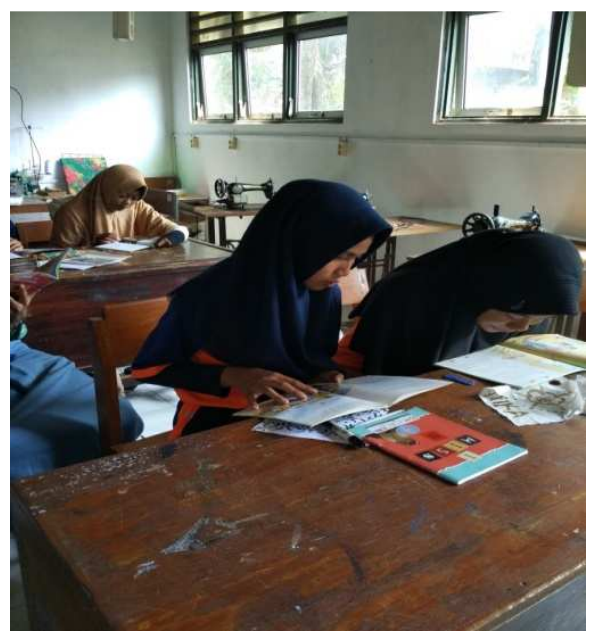

Gambar 3. Para peserta melakukan kegiatan pair-work 
Setelah pelatihan dilaksanakan, para peserta mengikuti post-test TOEIC yang bertempat di Laboratorium Bahasa LTC UMY. Baik pre-test maupun post-test sengaja diselenggarakan di luar sekolah dengan tujuan agar menjaga obyektivitas hasil tes serta memberi kesempatan para peserta untuk mengikuti tes dengan perangkat tes yang terstandar dan dikelola secara profesional oleh lembaga tes yang kredibel. Di ruang tes yang memang didesain untuk pelaksanaan tes kompetensi Bahasa Inggris, tes berjalan kondusif karena ruang tes yang nyaman (ber AC dan kedap suara). Dengan dukungan kenyamanan ruang tes, diharapkan bisa memicu ketercapaian hasil tes yang maksimal. Keikutsertaan peserta dalam tes TOEIC-like ditunjukkan dalam gambar 4 berikut ini.

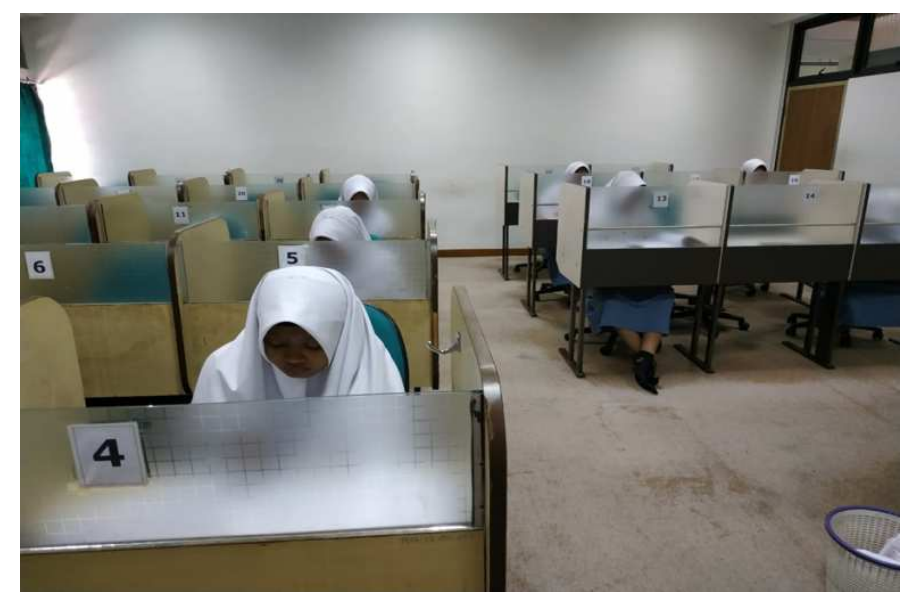

Gambar 4. Para peserta mengikuti post-test TOEIC-like

Hasil post-test yang ditunjukkan di tabel 3 di bawah ini menunjukkan bahwa dari 10 peserta yang mengikuti pelatihan dan post-test, 3 diantaranya mengalami kenaikan skor TOEIC meskipun tidak begitu signifikan, 2 diantaranya mengalami penurunan skor, sedang 1 orang memperoleh skor yang tetap (tidak berubah). Sementara itu, 4 peserta tidak mengikuti pre-test sehingga hasil post-testnya tidak bisa dipakai sebagai alat ukur pencapaian skor TOEIC mereka. Para peserta juga mendapatkan sertifikat TOEIC-like yang dikeluarkan oleh LTC UMY.

Tabel 3. Hasil post-test TOEIC

\begin{tabular}{cccc}
\hline No. & Nama & Skor post-test & Keterangan \\
\hline 1 & Adiannisa Quirella & Tidak hadir/tidak aktif & Tidak bisa diukur \\
2 & Amanda Wulansari & 240 & Skor naik \\
3 & Anisa Liam Sari & 135 & Tidak bisa diukur \\
4 & Febriani & 285 & Skor naik \\
5 & Fitri Nur Cahyani & 155 & Tidak bisa diukur \\
6 & Nadia Bela W & Tidak hadir/tidak aktif & Tidak bisa diukur \\
7 & Nadya Puspitasari & 210 & Tidak bisa diukur \\
8 & Nurul Atika O & 305 & Skor naik \\
9 & Rissa Nuraeni & 130 & Skor turun \\
10 & Sri Rahayu & 145 & Skor tetap \\
11 & Tarysa Bella & Tidak hadir/tidak aktif & Tidak bisa diukur \\
12 & Valen Flary E & 180 & Tidak bisa diukur \\
13 & Winda Eka D & 200 & Skor turun \\
\hline
\end{tabular}


Meskipun target untuk mencapai skor TOIEC 400 belum tercapai, ada indikasi bahwa melalui pelatihan TOEIC ini, para peserta mulai menunjukkan motivasi untuk meningkatkan kemampuan Bahasa Inggris mereka. Ada dua hal utama yang menjadi indikator naiknya motivasi peserta dalam meningkatkan kemampuan Bahasa Inggris mereka. Yang pertama, ini ditunjukkan dengan data bahwa siswa yang skor TOEIC-nya naik lebih banyak (3 orang) daripada peserta yang skor TOEIC-nya turun (2 orang) setelah mengikuti pelatihan. Yang kedua, jumlah peserta yang mengikuti post-test meningkat menjadi $100 \%$ dibanding peserta pretest yang hanya $50 \%$. Motivasi merupakan faktor yang tidak bisa diabaikan dalam proses belajar siswa. Motivasi merupakan hal yang penting karena merupakan alat untuk mencapai tujuan (DISŞLEN, 2013). Motivasi belajar merupakan aspek yang menggerakkan atau mendorong siswa sehingga kegiatan belajar bisa berlangsung dan tujuan yang sudah ditetapkan bisa tercapai (Kiswoyowati, 2011).

\section{KESIMPULAN}

Dari pelaksanaan kegiatan Pengabdian kepada Masyarakat skema Program Kemitraan Masyarakat dalam bentuk pelatihan TOEIC untuk meningkatkan kompetensi Bahasa Inggris siswi-siswi Tata Busana SMK Muhammadiyah Bangunjiwo, dapat disimpulkan hasil sebagai berikut:

1. Meskipun target untuk mencapai skor TOEIC 400 belum tercapai, ada hal-hal positif yang muncul dari hasil pelatihan TOEIC. Partisipasi peserta untuk mengikuti tes meningkat, dari yang semula 6 orang pada saat pre-test, menjadi 10 orang pada saat post-test. Selain itu, dari 6 orang yang mengikuti pre dan post test, 3 orang di antaranya mengalami kenaikan skor TOEIC pada saat post-test, 2 orang mengalami penurunan skor, sedangkan 1 orang skornya tetap.

2. Motivasi belajar para siswa terutama dalam upaya mengasah kemampuan berbahasa Inggris mereka perlu terus dijaga dan ditingkatkan, yaitu melalui metode pembelajaran yang interaktif dan menyenangkan. Salah satunya yaitu melalui kegiatan reading for fun yang bisa diterapkan seusai pelatihan TOEIC ini. Dengan kegiatan membaca, kosakata siswa akan bertambah, sehingga akan menunjang kemampuan mereka dalam berkomunikasi baik secara pasif maupun aktif dalam Bahasa Inggris. Untuk mengasah kemampuan mendengarkan mereka, pembelajaran melalui audio maupun multimedia (misalnya melalui lagu, film, percakapan-percakapan ringan dari audio) perlu diterapkan agar para siswa terbiasa mendapatkan fun exposure (paparan yang menyenangkan) tentang penggunaan keterampilan berbahasa.

3. Pelatihan TOEIC perlu diselenggarakan dengan menggunakan pendekatan student-centred learning, sehingga para peserta akan mendapatakan lebih banyak kesempatan untuk melakukan kegiatan-kegiatan maupun praktik penggunaan bahasa, dan merangsang kemandirian serta otonomi mereka dalam belajar. Hal ini akan menggerakkan sikap bertanggung-jawab para siswa dalam menentukan keberhasilan proses belajar mereka.

\section{UCAPAN TERIMA KASIH}

Penulis mengucapkan terima kasih kepada LP3M UMY yang telah mendanai kegiatan Pengabdian kepada Masyarakat skema Program Kemitraan Masyarakat ini, dan juga kepada SMK Muhammadiyah Bangunjiwo Bantul yang telah menjadi mitra yang baik sehingga Program Kemitraan Masyarakat ini bisa terakomodir dan berjalan dengan lancar. 


\section{DAFTAR PUSTAKA}

DİşLEN, G. (2013). The Reasons of Lack of Motivation From the Students' and Teachers' Voices. The Journal of Academic Social Sciences, 1(1), 35-35. https://doi.org/10.16992/asos.13

Fauzia. (2013). Peran Pengajaran Bahasa Inggris dalam Pendidikan Vokasi. Prooceding Seminar Nasional Pendidikan Vokasi UNY.

Handayani, S. (2016). Pentingnya Kemampuan Bahasa Inggris dalam Menyongsong ASEAN Community. 3, 102-106.

Ismailia, T., Budi, A. S., \& Zuhro, C. (2017). Pelatihan Test of English for International Communication ( TOEIC) di SMK Jember. 211-214.

Jones, L. (2007). The Student-Centered Classroom.

Kaimuddin, P. (2009). English Syllabus Design for College Students of Avionic Technology Makassar.

Kiswoyowati, A. (2011). Edisi Khusus No. 1, Agustus 2011. (1), 120-126.

Raja, N., \& Ahmad Saeed, P. (2012). INTERDISCIPLINARY JOURNAL OF CONTEMPORARY RESEARCH IN BUSINESS The Effectiveness of Group Work and Pair Work for Students of English at Undergraduate Level in Public and Private Sector Colleges. 155-163.

Umar. (2017). Using Barron' s TOEIC Preparation Course Package To Improve The Listening Skill For Vocational School. Journal of Educational Science and Technology, 3, 93-101.

Young, L. E., \& Paterson, B. L. (2007). Teaching Nursing: Developing a Student-centred learning Environment. Lippincott Williams \& Wilkins.

Yuliana, Y. G. S. (2016). Integrated Task-Based Learning: Sebuah Alternatif Teknik Peningkatan. 1(1), 22-29. 